\title{
ANTROPOLOGÍA VISUAL: DEL REGISTRO ETNOGRÁFICO AL CINE COMPARTIDO
}

\author{
VISUAL ANTHROPOLOGY: FROM THE ETHNOGRAPHIC RECORD \\ TO SHARED CINEMA
}

JaVIER EXPósito MARTín ${ }^{A}$

En este artículo se presenta una revisión diacrónica de la utilización de las herramientas audiovisuales como técnicas de investigación antropológica. Luego se aborda el cine etnográfico compartido, cuyo objetivo es la construcción de conocimiento de manera conjunta y participativa entre el realizador y los protagonistas del audiovisual, democratizando el proceso creativo e investigativo, generando reciprocidad, horizontalidad y revalorizando las tradiciones culturales, la autoestima y la identidad de la comunidad. Finalmente, se expone la metodología de la cámara colaborativa.

Palabras clave: Antropología visual, Registro etnográfico, Modos de representación, Cine compartido, Cámara colaborativa.

This paper presents a diachronic discussion of the use of audiovisual tools in anthropological work. It also analyzes shared and collaborative ethnographic cinema, the main goal of which is collaborative knowledge-building by the filmmaker and their actors, democratizing research and creative processes, generating reciprocation and horizontality, and reasserting cultural traditions, self-esteem and the communal identity. Finally, the methodology of the collaborative camera is discussed.

Keywords: Visual anthropology, Ethnographic record, Modes of representation, Shared cinema, Collaborative camera.

\section{INTRODUCCIÓN}

Desde los inicios la antropolgía se centró en el estudio de las imágenes simbólicas para descubrir las creencias religiosas y la cosmovisión del ser humano (Ardèvol 2004). Por su parte "la antropología visual lógicamente proviene de la creencia en que la cultura se manifiesta a través de símbolos visibles encajados en gestos, ceremonias, rituales y artefactos situados en entornos naturales o construidos... Si uno puede observar la cultura, los investigadores debieran ser capaces de emplear tecnología audiovisual para grabarla como datos sujetos a análisis y presentación" (Ruby 2002: 155).

La antropología visual ha utilizado los medios audiovisuales con dos objetivos fundamentales: a) "generar un producto audiovisual como objetivo vertebral de la investigación, b) aprovechar los textos audiovisuales preexistentes en cuanto documentos potenciales para la investigación" (Grau 2012: 164).

La disciplina no es reciente, ya que el cine ${ }^{1}$ y la fotografía etnográfica tienen más de cien años (Zirión 2015); además, es una especialidad interdisciplinaria que requiere del dominio de la antropología, las ciencias de la comunicación y las técnicas audiovisuales.

Los antropólogos que incorporaron la cámara en su trabajo de campo a finales del siglo xix lo hicieron

\footnotetext{
A Javier Expósito Martín, Universidad Complutense de Madrid. ORCID: 0000-0002-3890-0894. E-mail: javierexpositomartin2018@ gmail.com
} 
con un propósito claro: documentar las pautas culturales de los pueblos que estaban extinguiéndose tras la colonización europea. Filmaron bailes, rituales y otras muestras culturales considerando la cámara como la herramienta idónea para el registro de documentación etnográfica. Esto modificó para siempre las técnicas de investigación etnográfica y su difusión, ya que el uso de la cámara "supone, de alguna manera, pensar visualmente. Reflexionar no solo sobre el lenguaje, sino también sobre nuestra percepción visual. Nos obliga a pensar sobre cómo miramos" (Ardèvol 1994: 38).

Las tecnologías audiovisuales ayudan a conocer cómo viven, piensan, sienten y se relacionan los miembros de una comunidad. Son idóneas para investigar el patrimonio cultural, registrar y transmitir comportamientos y creencias, y para construir conocimiento compartido. Los documentales son vehículos de comunicación (Rodrigo-Mendizábal 1996) que sirven para difundir una cultura y para evaluar y estudiar al antropólogo o etnocineasta que los realiza. ${ }^{2}$

Un aspecto fundamental de este trabajo es ofrecer al lector los links de los documentales que considero claves para conocer la clasificación del cine etnográfico y la historia de la antropología visual.

\section{LOS ORÍGENES Y EL DESARROLLO DE LA ANTROPOLOGÍA VISUAL (1898-1950)}

Los primeros científicos que utilizaron el cine en la investigación etnográfica se interesaron en su potencial como "instrumento de documentación visual, es decir, como forma de registro documental" (Ardèvol 2006: 62). Franz Boas fue uno de los antropólogos pioneros en la utilización de la cámara cinematográfica y fotográfica al estudiar durante más de 40 años a los kwakiutl de Canadá, obteniendo y recopilando numerosas filmaciones y un extenso material etnográfico (Morris 1994: 55-66): "Clearly it is not an overstatement to suggest that Franz Boas should be regarded as a father figure in visual anthropology. He is at least partially responsible for making picture-taking a normative part of the anthropologist's field experience, a characteristic which has distinguished us from other students of the human condition" (Ruby 1980: 7).

En 1898, mientras Boas trabajaba en Canadá, el antropólogo británico Alfred Haddon junto con sus compañeros de la Universidad de Cambridge, utilizaba una cámara de cine para sus investigaciones etnográficas en las islas Murray y Mabuiag, del estrecho de Torres, entre Australia y Nueva Guinea. ${ }^{3}$ Haddon, impresionado por el poder de la nueva tecnología, escribió a su colega Baldwin Spencer: "Realmente debes llevar un cinematógrafo [...] Es una pieza indispensable del aparato antropológico" (Henley 2001: 2). Spencer siguió su consejo y en 1901 llevó una cámara para realizar sus estudios antropológicos en Australia Central y del Norte (Henley 2001).

Poco después, en 1922, se estrenó un documental clave en el desarrollo de la antropología visual: Nanook of the North. Su director, Robert Flaherty, convivió más de dos años con el protagonista de su obra, Nanook, y su familia, en la región nororiental de la bahía de Hudson del Ártico canadiense.

En el documental, el director muestra la capacidad de adaptación del ser humano y su audacia para sobrevivir en el Ártico. Para Flaherty lo fundamental era captar la esencia de estas personas y transmitirnos su espíritu, al igual que el de la humanidad representada en Nanook y su familia. Su objetivo fue reflejar las antiguas costumbres de los inuits antes de la llegada del hombre blanco, y para conseguirlo, reconstruyó fílmicamente algunas de estas tradiciones junto con Nannok. ${ }^{4}$ Flaherty pasó de la observación a la "puesta en escena". No se contentó con registrar la cotidianidad de sus protagonistas, sino que realizó una obra lírica reconstruyendo la forma de vida ancestral de los inuits. En la película hay una progresión argumental, ya que comienza con imágenes divertidas y anecdóticas de la familia de Nanook, pero paulatinamente va mostrando la dureza de sus vidas. ${ }^{5}$ La construcción fílmica fue influenciada por el pionero del cine de ficción David Griffith. Un ejemplo de ello es el montaje paralelo en la secuencia de la construcción del iglú. ${ }^{6}$

Flaherty adoptó un modo de trabajar, único hasta entonces, basado en la colaboración entre el director y los protagonistas. En vez de hacer una película sobre Nanook, realizó una película con Nanook. Años más tarde, el antropólogo Luc de Heush definió esta metodología como 'cámara participante' (Rouch 1975). Para Jean Rouch, las bases de esta cámara fueron la iniciativa cinematográfica de la puesta en escena-mettre en scène la réalité- y la colaboración de Flaherty con Nanook (Ardèvol 1994: 90).

En forma paralela al trabajo de Flaherty, en la URSS destacaba el estilo de filmación de Dziga Vertov. Las realizaciones de ambos sirvieron para establecer la metodología del cine etnográfico. 
Vertov (1974) creó el "cine-ojo", un método de estudio científico-experimental y un tipo de cine que buscaba registrar la realidad social de manera espontánea, sin utilizar la narración textual. Para retratar la realidad y la vida social prescindió de guiones, actores, decorados, iluminación y de los mecanismos del cine de ficción (Vertov 1963). En 1929 realizó El hombre de la cámara, una película compuesta por miles de planos (muchos de muy corta duración) que mostraban la vida cotidiana en San Petersburgo. Vertov filmó, sin planificar, instantes de la realidad que le rodeaba. A dichos instantes los denominó kino-fraza, "frases fílmicas", a las que posteriormente les dio sentido en la sala de montaje (Ardèvol 2006, cap. II: 57). ${ }^{7}$ Esta obra es considerada un precedente del cine reflexivo, ya que en muchas secuencias se observa al camarógrafo filmando, explicitándose así el modo de producción de la película (Ardèvol 2006, cap. II: 58). La metodología de Vertov influyó notablemente en Rouch a la hora de plantear su teoría del cinéma vérité.

Flaherty y Vertov realizaron sus películas casi simultáneamente a los estudios de Malinowski, sin embargo, a diferencia de este, pasaron desapercibidos hasta 1968, cuando, por un lado, el cineasta francés Jean-Luc Godard fundó el Grupo Dziga Vertov y, por otro, Rouch recuperó la metodología participativa de Flaherty y el cine directo de Vertov (Rouch 1975).

En la década de 1930, los antropólogos Margaret Mead, discípula de Boas, y George Bateson, discípulo de Haddon, filmaron juntos gran cantidad de material audiovisual en Nueva Guinea y Bali (Grau 2008). Su objetivo no fue realizar documentales, sino utilizar las herramientas audiovisuales en el registro etnográfico con la finalidad de captar imágenes para su posterior análisis. Les interesaba recoger "tipos de comportamiento no verbal, para los cuales no existían ni vocabulario, ni métodos conceptualizados de observación, y donde la observación debía preceder a la codificación" (Mead 1963: 174). En 1952 editaron parte del material filmado en Bali y produjeron el documental Trance and dance in Bali, en el que se describe el ritual, contenido en la narración de Mead, excluyendo la visión de los participantes (Jackins 1988). ${ }^{8}$

En las décadas de 1950 y 1960, jóvenes antropólogos estadounidenses comienzan a realizar documentales etnográficos. The hunters (1958), dirigido por John Marshall (con la colaboración de Robert Gardner), fue "el primer film etnográfico norteamericano que ganó atención a nivel mundial” (Ruby 2002: 162).
En 1963, Gardner filmó en Nueva Guinea el documental Dead birds, con la colaboración de Karl Heider. Gracias a los trabajos de Marshall, Gardner y Timothy Asch, "el cine se ha transformado en una herramienta educativa de gran utilidad para los antropólogos culturales de los Estados Unidos" (Ruby 2007: 13).

En 1972, Sol Worth y John Adair publicaron un libro pionero, Through navajo eyes: an exploration in film communication and anthropology, que se ha convertido en un clásico de la antropología visual. Worth y Adair prestaron cámaras a indígenas navajos y les enseñaron a utilizarlas para que se autorrepresentaran, lo que suponía cuestionar la autoridad y objetividad del antropólogo. El propósito era interpretar las películas realizadas por los nativos para conocer su forma de mirar el mundo a través de un análisis semiótico de las imágenes (Cárdenas \& Duarte 2011).

\section{CLASIFICACIÓN DEL CINE ETNOGRÁFICO: LOS MODOS DE REPRESENTACIÓN}

En las últimas décadas del siglo XX se teoriza el cine etnográfico y se plantean diferentes formas de definirlo y clasificarlo. En 1976, Karla Heider publicó el libro Ethnographic film (Lisón 2014), en el que teoriza sobre el film etnográfico y sistematiza sus reglas. Argumentaba que la investigación se efectuaba antes de utilizar las herramientas audiovisuales, por lo tanto, la cámara no era necesaria en ese proceso. "El estilo de producción, la forma de mover la cámara, responde a una actitud de documentar audiovisualmente las tesis defendidas por el antropólogo" (Ardevòl 1998: 221-222).

El modo de representación se define como "la forma en que se configura el film, e incluye el estilo de filmación y edición del material, así como el modelo de colaboración" (Ardèvol 1994: 64). A continuación, se exponen sintéticamente los puntos más importantes de los modos de representación del cine etnográfico, según la clasificación de Elisenda Ardèvol (2006) y se señalan ejemplos audiovisuales de cada uno de ellos.

\section{Cine exposicional o expositivo}

Aparece en los primeros momentos del cine documental, cuando no había sonido directo y se incorporaban subtítulos para añadir información a las imágenes. Más 
tarde, el cine se sonorizó y el director utilizó la voice over o voz en off para comunicar su interpretación de las imágenes filmadas.

En el cine exposicional se observa una fuerte autoridad del narrador que guía al espectador a través de la voz en off, las imágenes apoyan la descripción e ilustran los postulados defendidos por el director. La estructura narrativa de la película depende del desarrollo conceptual y no del acontecimiento registrado, por ello hay una elaboración pormenorizada del guion. Se ha utilizado para dar a conocer una crítica cultural, una denuncia social o, por el contrario, una defensa del orden establecido.

En este tipo de cine puede haber entrevistas que, en "función de los intereses del realizador, son pruebas empíricas que incorpora para dar más fuerza y convicción a su discurso, que se presenta como objetivo y veraz" (Ardèvol 2006, cap. II: 55).

Ejemplos de este cine los encontramos en los documentales La corporación, instituciones o psicópatas (2003), de Mark Achbar y Jennifer Abbott; 9 Trance and dance in Bali (1952), de Bateson y Mead, y Yanomamis (1983), de Luis Pancorbo, pionero del cine etnográfico en España. ${ }^{10}$

\section{Direct cinema}

Los realizadores más reconocidos del Direct cinema son Richard Leacock, Richard Drew, Donn Pennebaker y los hermanos David y Albert Maysles.

En este género, el cineasta graba un hecho en el que tanto su cámara como él mismo pasan desapercibidos para los protagonistas; el director "juega el rol de un invitado no implicado" (Nichols 1991: 39), minimiza "su contacto con los sujetos durante la filmación para no influenciar su comportamiento" (Ardèvol 2006, cap. II: 87) y solicita que nadie actúe o diga algo a la cámara, para que la grabación sea espontánea. Por ello, propone filmar cerca de los protagonistas, "cámara en mano", con el objetivo de que los planos sean dinámicos y transmitan proximidad. Durante la edición se procura no añadir voz en off ni música extradiegética. Un ejemplo de cómo utilizar este modo de representación se puede ver en el documental del autor Zaña, recuperando el pasado. La herencia musical africana en el norte de Perú. ${ }^{11}$

\section{Cine observacional}

Colin Young concibió el cine observacional como el hecho de "filmar a la gente en su ambiente natural mientras realiza las cosas que hace habitualmente, rechazando la estructura dramática" (Young 1975: 68). Al igual que el Direct cinema, su objetivo es mostrar la realidad espontáneamente, intentando no alterarla. El resultado final es la grabación "en bruto", sin intervenir en ella, y con una edición lineal para que, quien lo vea, pueda sacar sus propias conclusiones al no estar modificada (Ardèvol 2006, cap. II: 90).

En el cine observacional la cámara adopta una posición estratégicamente distante, de forma que pueda captar el máximo de interacciones desde un punto fijo: "ser como una mosca en la pared" (Ardèvol 2006: 73). El montaje es más rígido que en el Direct cinema, sin permitir tanta libertad al realizador. Un ejemplo se puede ver en la primera parte del documental The ax fight (1975), de Timothy Asch y Napoleón Chagnon, ${ }^{12}$ que se divide en cuatro partes y un epílogo. En la primera secuencia se ve una pelea con mazos y hachas tal y como la registró la cámara hasta que se terminó la bobina. Este material se incorporó a la película sin interrupciones: "la cámara permaneció fija en su punto de observación con ocasionales zooms, procurando siempre enfocar el lugar donde se produce una mayor acción. El director advierte que las escenas han sido captadas espontáneamente y que son confusas para el propio observador" (Ardèvol 2006: 100).

La primera parte de la película es idónea para cursos de antropología. Los estudiantes pueden interpretar lo que sucede originalmente, ya que los realizadores no interaccionan con el suceso, filman desde una distancia prudencial mediante una cámara pasiva $\mathrm{y}$, posteriormente, en la edición no cortan la secuencia, dejándola transcurrir íntegramente.

\section{Cinéma vérité}

Frente al estilo observacional, desarrollado a partir del Direct cinema en EE.UU., el antropólogo francés Jean Rouch planteará el Cinéma vérité como una forma de antropología compartida que propone un diálogo con los protagonistas y su participación en parte de la creación de la película. Rouch (1975) combinó la teoría del cine-ojo -kino-glaz- de Vertov, con la metodología participativa de Flaherty. 


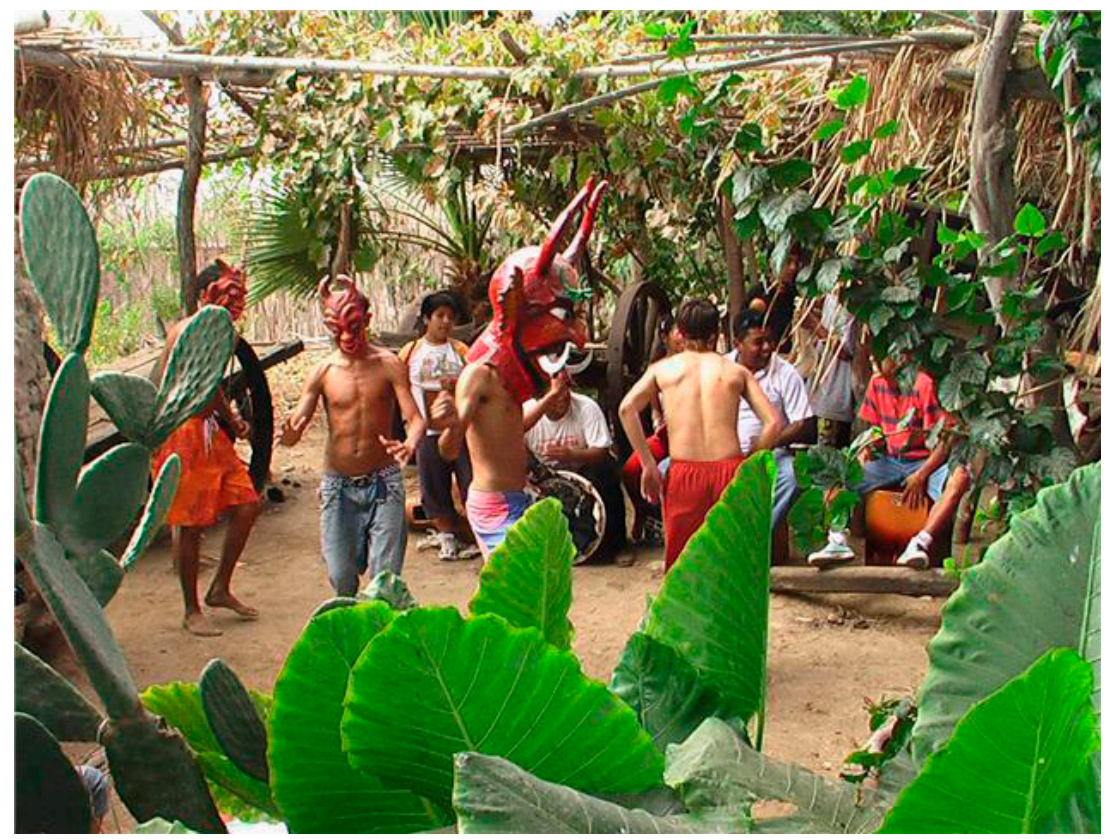

Figura 1. Ejemplo de Cine-trance en el baile de los diablitos del documental Zaña, recuperando el pasado. La herencia musical africana en el norte de Perú. (Fotografía del autor). Figure 1. Example of cinéma-trance in the dance of the diablitos from the documentary Zaña, recovering the past. African musical heritage in the north of Peru. (Photograph by the author).
En el Cinéma véritéla presencia de la cámara propicia que se desarrollen los acontecimientos, no se esconde, provoca la reacción de los protagonistas e interactúa con ellos (Ardèvol 1997). ${ }^{13}$ Para Rouch, el cine construye su verdad, una verdad cinematográfica (Bouhaben 2014). El antropólogo francés propone que el etnógrafo sea también cineasta, porque "aunque sus producciones sean técnicamente inferiores a las de los profesionales del medio, tendrán la irremplazable cualidad de un contacto real entre la persona que filma y las personas filmadas" (Rouch 1975: 92). En algunos de sus documentales solicitaba a los protagonistas que actuaran representando su propia vida y colaboraran en el proceso de filmación, para que el argumento tomara forma durante el proceso de producción de la película (Ardèvol 1997).

Influenciado por Flaherty, Rouch mostraba a sus protagonistas el rodaje del documental para que estos compartieran sus impresiones con él y se generaran dinámicas de construcción participativas. ${ }^{14}$

Otra propuesta de Rouch fue el Cine-trance, que consiste en una alteración del estado de conciencia, provocado espontáneamente durante la filmación de un documental etnográfico y experimentado por los protagonistas y/o el realizador (fig. 1). Al respecto, Rouch expone: "Cuando tengo una cámara y un micrófono, yo no soy el yo mismo de siempre, estoy en un estado distinto, en un cine-trance" (Eaton 1979:
50). Como ejemplo de Cinéma-trance, ver Les maîtres fous $(1975)^{15}$ y un fragmento de Zaña, recuperando el pasado. La herencia musical africana en el norte de Perú (Expósito 2015a). ${ }^{16}$

\section{Cine participativo}

El antropólogo David MacDougall desarrolló, a principios de la década de 1980, el Participatory cinema. Critica las metodologías del direct cinema y del cine observacional basadas en la "invisibilidad" del realizador y de la cámara y propone la colaboración entre el realizador y la comunidad filmada, invitando a los protagonistas a participar en la producción del documental para crear la película entre todos. Apuesta por "la intervención del sujeto filmado en la composición de la imagen que se construye sobre su propia forma de vida, así como replantear los objetivos de la filmación etnográfica" (Ardèvol 1997: 145).

MacDougall considera que los protagonistas de un documental se comportan de forma más espontánea cuando están siendo grabados, que cuando son observados por un etnógrafo que utiliza un cuaderno de notas: "Un sujeto con una cámara tiene un trabajo visible para todos, no es un visitante importante e inquisitorial, como, de hecho, se percibe muchas veces al investigador de campo en una comunidad pequeña" (Ardèvol 2006, cap. 


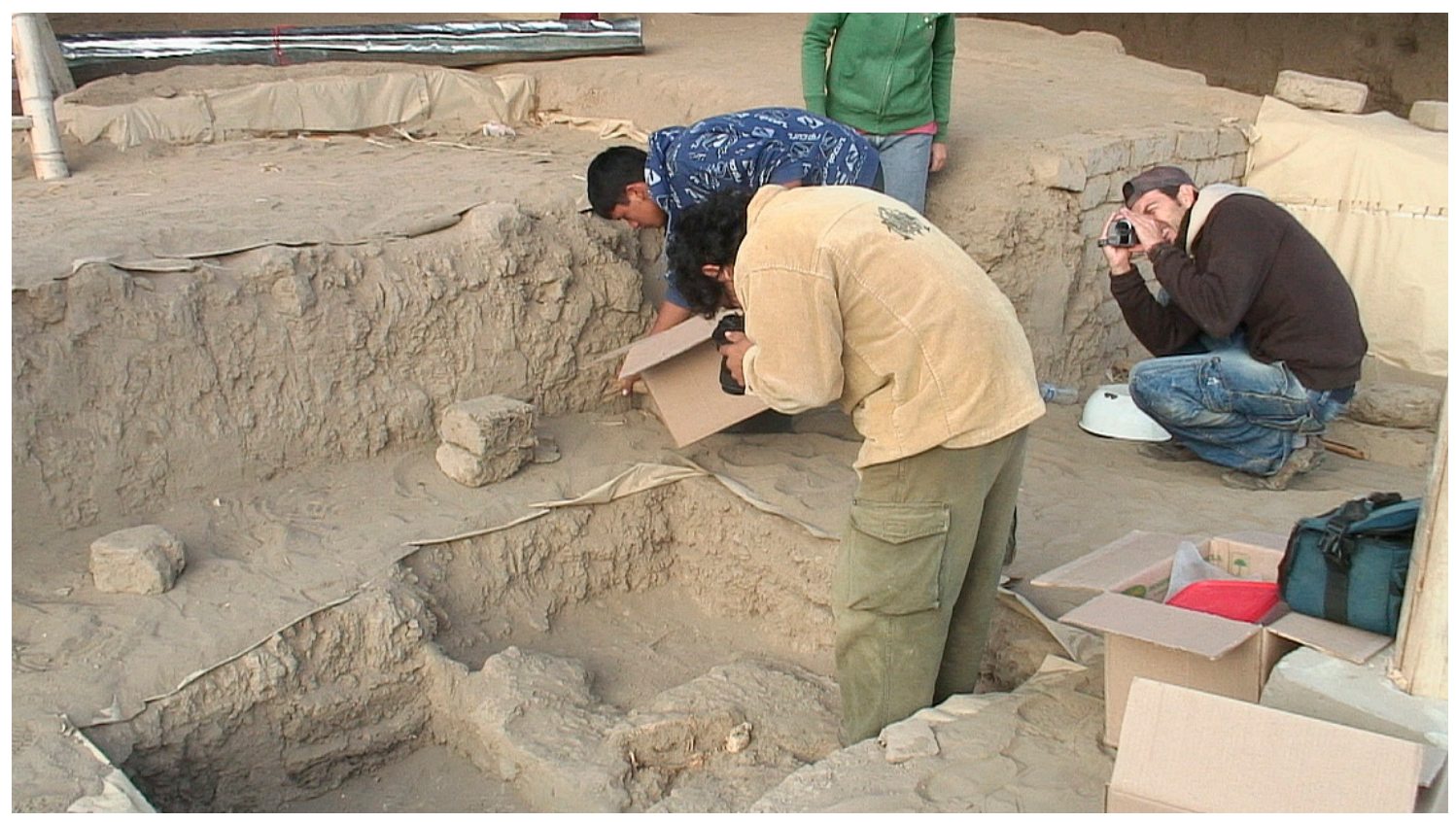

Figura 2. El arqueólogo Ignacio Alva en el documental Ventarrón, un proyecto de vida. Arqueología e identidad lambayecana. (Fotografía del autor). Figure 2. Archaeologist Ignacio Alva in the documentary Ventarron, a life project. Lambeyacan archaeology and identity. (Photograph by the author).

III: 16). El cine participativo cuestiona la superioridad del antropólogo sobre los protagonistas del documental y propone que el cine etnográfico sea un encuentro cultural (Ardèvol 1997). El objetivo del investigador, al realizar un documental etnográfico, es desarrollar una investigación científica, pero debe considerar que los protagonistas, por su parte, también pueden tener intereses políticos o culturales (MacDougall 1994).

Un ejemplo de cine compartido es el documental del autor (fig. 2) Ventarrón, un proyecto de vida. Arqueología e identidad lambayecana (2015b). ${ }^{17}$

\section{Cine reflexivo}

A finales de la década de 1970 y durante la década de 1980 se desarrolla teóricamente el cine reflexivo. Jay Ruby, su más destacado representante, cuestiona la noción de objetividad y opta por dar un giro hacia una antropología interpretativa y reflexiva (Ruby 1995). "Ruby propondrá que el cine etnográfico introduzca la metodología empleada dentro de la estructura del filme y que el realizador explicite su posición personal frente a los sujetos filmados a la vez que su actitud frente al objeto de estudio" (Ardèvol 2006, cap. viI: 7).
En este cine, las autodescripciones nativas toman protagonismo, siendo los propios sujetos los que se expresan en la película. Se propone que los protagonistas realicen su propio documental, dando relevancia a la autorreflexividad y a la autorrepresentación: "Se cuestiona la idea de que sea necesaria una traducción cultural. Los sujetos pueden hablar por sí mismos y ser ellos, y no el cineasta o el antropólogo, quienes cuenten su vida a la audiencia, directamente y sin intermediarios" (Ardèvol 2006, cap. III: 4). Al igual que Vertov, Ruby (1995) propone mostrar al espectador la tecnología utilizada en la creación de la ilusión cinematográfica.

En referencia a la noción de autorreflexividad, propongo ver dos secuencias del documental Les glaneurs et la glaneuse (2000), de Agnès Varda. ${ }^{18}$ Con respecto a las autorrepresentaciones, recomiendo ver el documental en el que participé en su creación: Cso La traba primer año de okupación (La Plataforma 2007). ${ }^{19}$ También ver $O$ dia em que a lua menstruou (2004), realizado por miembros del pueblo indígena kuikuro, con la coordinación de Vincent Carelli y el antropólogo Carlos Fausto. ${ }^{20}$ Jay Ruby propone como ejemplo de cine etnográfico reflexivo el documental Crónica de un verano de Jean Rouch (1961). 


\section{Cine evocativo}

Durante las décadas de 1980 y 1990 surgió la denominada "crisis de la representación" (Marcus \& Fischer 1986). Esta "crisis" en la antropología visual originó la división entre los realizadores que retomaron las tesis del cine observacional y del direct cinema buscando captar la vida de manera espontánea y los que optaron por realizar trabajos audiovisuales más políticos o artísticos. ${ }^{21}$ A esta última división pertenece el cine evocativo, que deconstruye la estructura clásica del cine documental.

Este cine reflexiona sobre cómo capturar las estructuras internas de una cultura; critica tanto el argumento del cine participativo, que propone que los protagonistas "impriman en el celuloide sus estructuras culturales" (Ardèvol 2006, cap. III: 63), como las nociones de objetividad e invisibilidad del cine observacional, dando relevancia a la subjetividad del realizador y del espectador (Minh-Ha 1990: 21).22

\section{EL CINE ETNOGRÁFICO COMPARTIDO EN LA ACTUALIDAD}

En las últimas décadas, se ha desarrollado, especialmente en Latinoamérica, un tipo de cine etnográfico basado en la colaboración entre el investigador y los protagonistas del documental. Esta modalidad plantea que el proceso creativo e investigativo se realice de manera colectiva, dando una gran importancia a la cámara como herramienta para el diálogo, la interacción y la reciprocidad. El cine compartido adquiere sentido en la actualidad como forma de contrarrestar el poder de los medios de comunicación hegemónicos, los cuales están al servicio de intereses económicos y políticos. Por esto, considero que es necesario construir $y$ dar visibilidad a otras formas de mirar y reflejar la realidad social, política y cultural.

En sus orígenes, el cine compartido está relacionado con diferentes proyectos que nacieron a finales del siglo $\mathrm{xx}$ en Latinoamérica, como por ejemplo Videos nas aldeias, de Vincent Carelli, el Proyecto de Video Kayapó, de Terence Turner, y el Proyecto cmp/Promedios.

El proyecto Video nas aldeias, fundado en 1986, tiene como objetivo apoyar las luchas de los pueblos indígenas para fortalecer sus identidades y sus patrimonios territoriales y culturales, utilizando para ello recursos audiovisuales en una producción compartida con los pueblos indígenas.
Por su parte, el Proyecto de Video Kayapó "es uno de los casos mejor documentados de producción de video indígena en colaboración con un antropólogo y sirviendo a los propósitos de ambos" (Banks 2008: 114). El antropólogo Terence Turner $(1990,1992)$ ayudó a los kayapó a conseguir sus primeras cámaras y un equipo de edición para que realizaran sus propios audiovisuales.

El Proyecto CMP/Promedios se inició a principios del siglo xxi en México. Su objetivo fue enseñar el uso de herramientas audiovisuales en comunidades indígenas de Chiapas y Guerrero. "El trabajo de vídeo nos ha conmovido realmente; tiene gran importancia para ayudarnos a construir nuestra historia indígena. Podemos ver que seremos capaces de hacer muchas cosas por nuestro bienestar y el futuro de nuestros hijos" (Estella, realizadora audiovisual zapatista, en Halkin 2006: 71). En este proyecto, los participantes se organizaron colectivamente, sin directores ni estructuras jerarquizadas, y los temas y contenidos de los audiovisuales se acordaron por consenso. Estas autorrepresentaciones se expusieron en las conferencias académicas de la American Anthropological Association y de la Latin American Studies Association. Según Alexandra Halkin, exdirectora de este proyecto, "las comunidades en Chiapas se adaptan a la tecnología audiovisual como una importante herramienta de comunicación interna, de preservación cultural, de derechos humanos y como un vehículo para comunicar sus propias verdades, historias y realidades al mundo exterior. La habilidad de grabar, editar y distribuir la propia historia es vital para el funcionamiento de la sociedad" (Halkin 2006: 92).

Desde hace más de una década, diferentes realizadores (Mora 2015, Expósito 2007, Bruzón 2017, Henríquez 2017, Sandoval 2017, Zirión 2015) hemos desarrollado proyectos de investigación etnográfica junto con diferentes comunidades (fig. 3).

El antropólogo Pablo Mora realizó un trabajo de investigación en la comunidad yukuna de Puerto Córdoba (Colombia) y ofreció un taller audiovisual a los indígenas. Posteriormente, produjeron de manera compartida el audiovisual Crónica de un baile de muñeco (2003), la comunidad participó en la investigación, el guion, la grabación y la edición: “La realización cooperativa de esta obra permitió a los indígenas establecer una relación directa con los lenguajes audiovisuales y descubrir nuevas formas de transmisión de sus memorias rituales; para los antropólogos involucrados significó un 


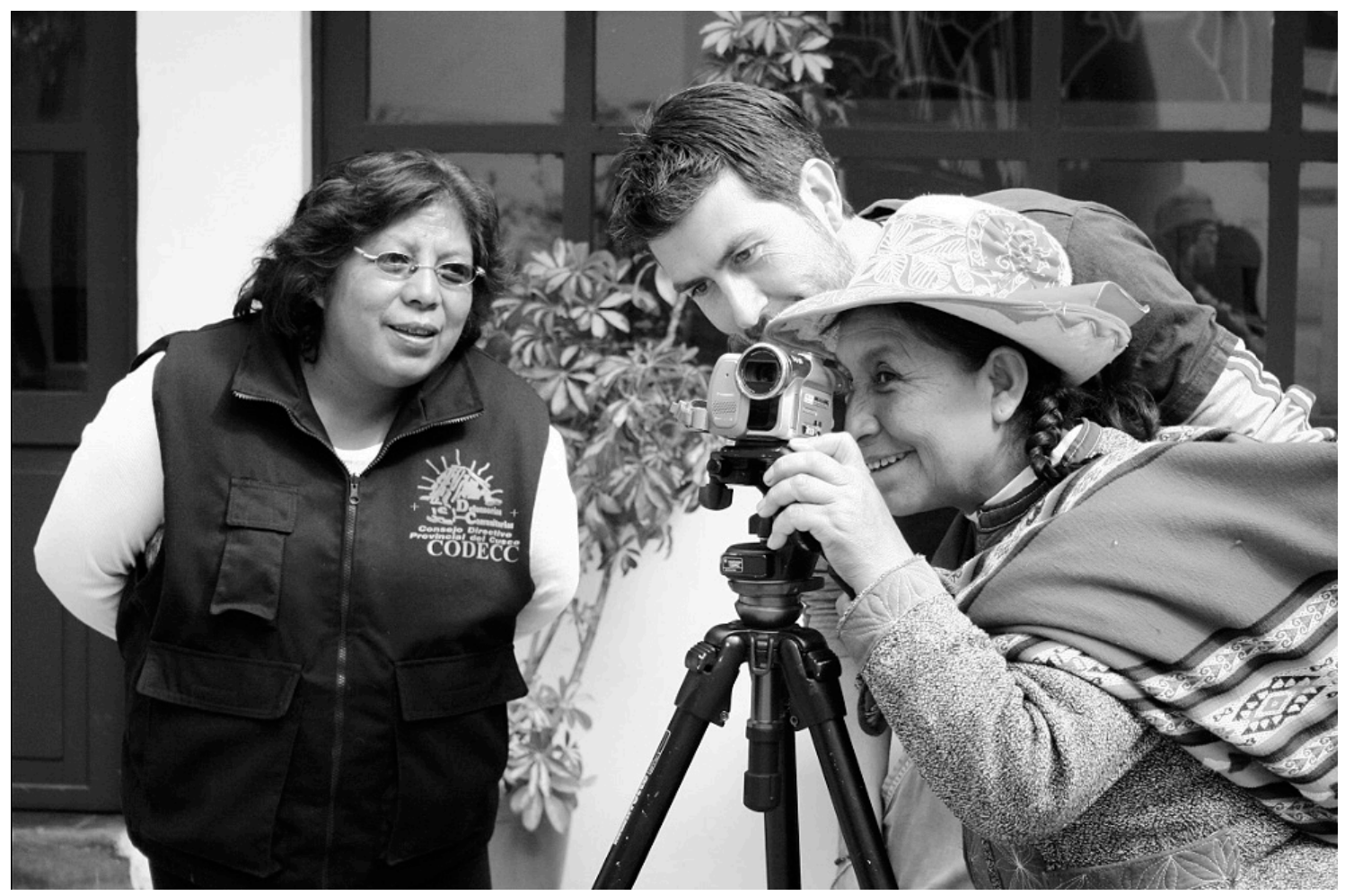

Figura 3. El autor junto a Guadalupe Cuba Huamani, Defensora Comunitaria de Cusco. (Fotografía: Asociación Quisca). Figure 3. The author with a Community Advocate from Cusco. (Photograph: Quisca).

cuestionamiento profundo de sus métodos de trabajo etnográfico" (Mora 2015: 34).

De este trabajo se hicieron tres versiones: una autorial con una duración de 90 minutos, otra de 52 minutos, destinada a la emisión en televisión, y una tercera, de 6 horas, para la comunidad. "Cada una de ellas transmite informaciones particulares, tiene distintos ritmos de montaje y obedece a las preferencias de públicos distintos" (Mora 2015: 34).

En el año 2012, Juan Sandoval desarrolló su proyecto de investigación colaborativa en Veracruz (México). ${ }^{23}$ Su objetivo fue construir conocimiento colectivamente, mediante el uso de cámaras de video. Durante su trabajo "los sujetos que se involucraron tomaron un rol activo y participante: la investigación no estuvo restringida al investigador, sino que todos los participantes tuvieron la capacidad de investigar y con ello contribuir desde sus propios análisis a las respuestas que la investigación buscó responder" (Sandoval 2017: 167).

El antropólogo Eduardo Henríquez comenzó su trabajo en Santo Domingo de los Colorados (Ecuador), con el propósito de reflexionar sobre el uso de la cámara en el trabajo etnográfico audiovisual como dispositivo de diálogo, interacción y reflexión (Henríquez 2017: 96). En el año 2013, durante su investigación realizó una etnografía audiovisual en la que destacó "la cámara como mediador entre productor informal y etnógrafo audiovisual" (Henríquez 2017: 99).

Otro ejemplo de este modo de hacer películas e investigaciones etnográficas se aprecia en el trabajo que Luis Bruzón está desarrollando en Centroamérica. En el año 2016 realizó en Guatemala Los guardianes del tiempo (fig. 4), implementando una observación participante con "un alto nivel colaborativo en la relación investigador-participantes” (Bruzón 2017: 53). Uno de los logros de la investigación fue contribuir "a una (re) construcción colectiva de sentidos culturales tendentes a fortalecer la identidad del municipio" (Bruzón 2017: 56), además, una vez finalizado el documental efectuó proyecciones en la comunidad (Bruzón 2017: 54).

No puedo dejar de mencionar otros ejemplos de realizadores, asociaciones y coordinadoras que han 


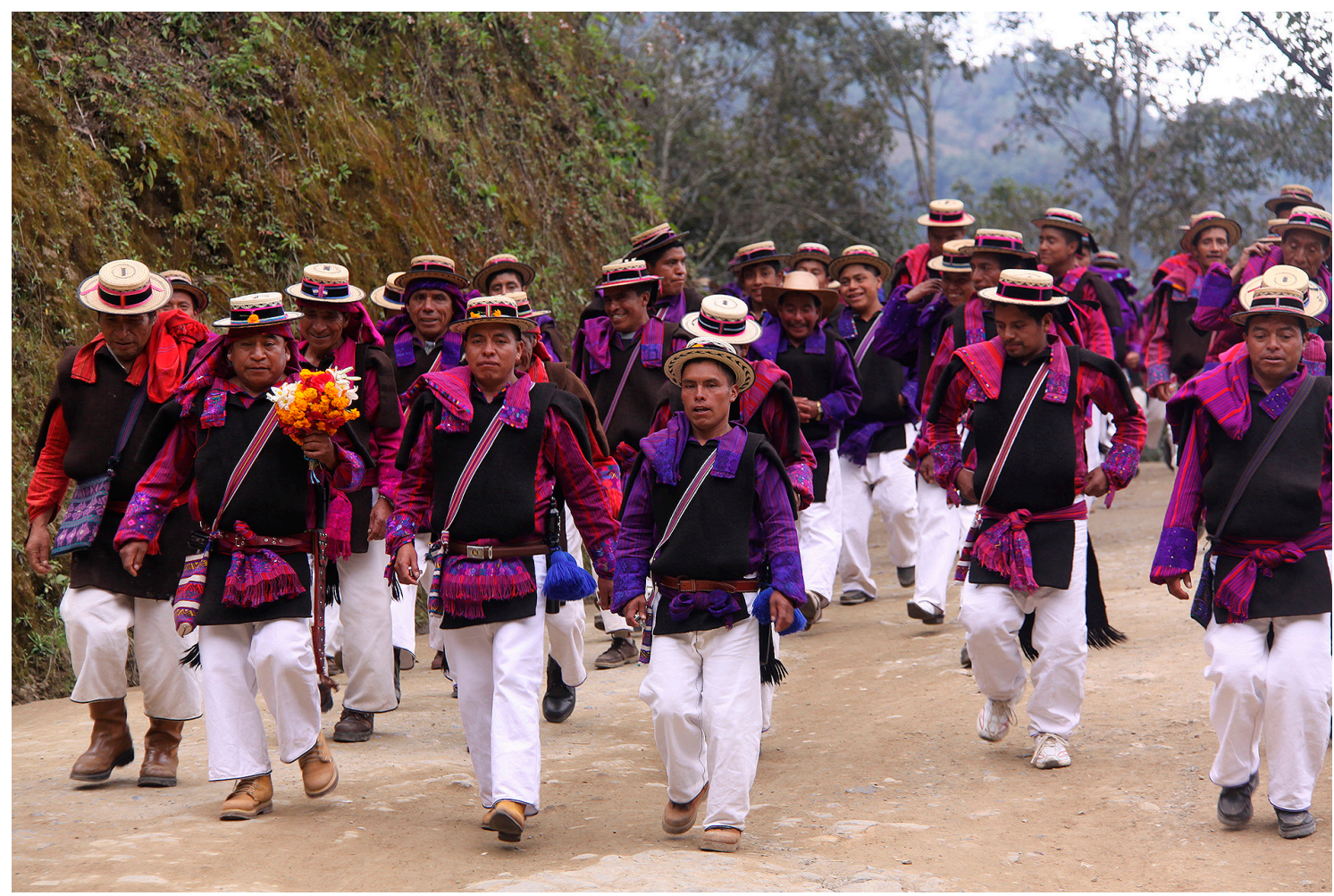

Figura 4. Comunidad maya de San Juan de Atitán (Guatemala), en el documental Los guardianes del tiempo. (Fotografía: Luis Bruzón). Figure 4. Mayan community of San Juan de Atitán (Guatemala) in the documentary The keepers of time. (Photograph: Luis Bruzón).

desarrollado métodos de colaboración participativa con diferentes comunidades en Latinoamérica, y que por motivos de espacio no expondré extensamente en este trabajo.

En primer lugar, la Coordinadora Latinoamericana de Cine y Comunicación de los Pueblos Indígenas (CLACPI). Dicha entidad nació en México durante el I Festival Latinoamericano de Cine y Video de los Pueblos Indígenas, cuando Claudia Menezes, antropóloga brasilera, directora del Museo do Indio de Río de Janeiro y profesora en talleres de uso del video a indígenas, propuso a los organizadores y participantes conformar una plataforma que permitiera dar continuidad a la experiencia del primer festival (Bermúdez 2013: 23). Desde entonces, CLACPI es un referente en la comunicación audiovisual indígena latinoamericana.

Luego en 1994, en Oaxaca, México, nace el primer Centro de Video Indígena bajo la iniciativa de la Transferencia de Medios Audiovisuales del INI. Su director durante el período 1994-1997 fue el realizador canadiense-italiano Guillermo Monteforte Bazzarello. El Centro de Video
Indígena tenía como fin ser un foro de intercambio de ideas entre distintos realizadores y ofrecer entrenamiento y capacitación para el uso del video en las comunidades. Gracias a este centro, numerosos indígenas aprendieron a utilizar las herramientas audiovisuales (Wortham 2007). En 1997, Monteforte se aleja del INI y crea una organización independiente del Estado, llamada Ojo de Agua Comunicación (Wortham 2007), definida como:

\footnotetext{
Una organización civil de comunicadores que, mediante la producción, difusión y capacitación en video, impulsa en las comunidades indígenas el uso y apropiación de herramientas de comunicación, creando y apoyando formas de expresión propias que promuevan la diversidad y reduzcan la desigualdad socioeconómica y política de los pueblos indígenas. El trabajo de Ojo de Agua Comunicación ha puesto a México, y especialmente al estado de Oaxaca, en la mira internacional, gracias a la capacitación y promoción del video indígena que han emprendido desde hace más de 10 años (Catálogo Raíz de la Imagen 2006 ).
}

En Bolivia destacan los trabajos del Centro de Formación y Realización Cinematográfica (CEFREC) y de 
la Coordinadora Audiovisual Indígena Originaria de Bolivia (СAIB). CEFREC, fundada en 1989, se convirtió en un referente en la organización de "talleres de realización audiovisual, comunicación y, desde 2004, de liderazgo y derechos" (Sanjinés 2013: 34). CAIB, al igual que CEFREC, desarrolla "una labor de fortalecimiento, acompañamiento y trabajo de acuerdo con los lineamientos de las Confederaciones Indígenas Originarias de Bolivia. Somos un equipo mixto de indígenas y no indígenas y muchos de nuestro equipo de profesores son indígenas" (Sanjinés 2013: 37). Estas organizaciones son un ejemplo de trabajo solidario, colaborativo y colectivo que están "desarrollando una mirada crítica tanto a la sociedad como hacia dentro, la visión indígena propia, descolonizadora, con permanente reflexión en torno a la identidad" (Sanjinés 2013: 37).

Desde la CLACPI, surge en Ecuador el año 2008 la Corporación de Productores Audiovisuales de las Nacionalidades y Pueblos (CORPAnP) (Champutiz 2013). Durante ese año y el siguiente realizaron 24 documentale, muchos de los cuales se enfocaron en trabajar la administración comunitaria a través de diversos temas, como soberanía alimentaria, derechos indígenas, de la mujer o educación. "La mayoría de los temas responden a esta dinámica. Nosotros, como venimos de organizaciones de base de lo que es el movimiento indígena, lo que hacemos es trabajar en el acompañamiento y fortalecimiento organizativo de dichas organizaciones de base" (Champutiz 2013: 125).

En Colombia se encuentra el Centro de Comunicaciones Zhigoneshi, dependiente de la Organización Indígena Gonawindúa Tayrona. Su director, Amado Villafaña Chaparro apuesta por la autorrepresentación comunitaria a través de las imágenes y los sonidos:

\footnotetext{
El conocimiento y la imagen es de propiedad colectiva de los pueblos indígenas, y están ante un peligro de saqueo. Cuando una persona que no pertenece a nuestro pueblo hace un documental, una fotografía o un libro, comienza a andar por el mundo hablando por nosotros, y nosotros no lo hemos escogido para que nos represente, eso es algo que debemos hacer nosotros, de esta manera nos autorepresentamos (Villafaña 2013: 138).
}

Por último, se destaca el trabajo del Centro de Culturas Indígenas del Perú (CHIRAPAQ), asociación que tiene como objetivo "desarrollar una comunicación indígena desde los pueblos mismos, para proyectarse al mundo. CHIRAPAQ promueve la comunicación como parte del tejido articulador para el fortalecimiento de los pueblos y organizaciones indígenas, así como la construcción de una visión ideológica y política propia según la historia, la realidad y cultura de nuestros pueblos" (http://chirapaq. org.pe/es/nosotros/quienes-somos).

\section{Características del cine compartido}

El cine compartido tiene como objetivo la construcción de conocimiento de manera conjunta y colaborativa entre el realizador y los protagonistas del audiovisual, teniendo en cuenta que "los antropólogos tienen la obligación ética primaria hacia las personas, especies y materiales que estudian y a las personas con quienes trabajan. Estas obligaciones pueden ser superiores a la meta de obtener nuevo conocimiento y por ello conducir a la decisión de no llevar a cabo o de discontinuar proyectos de investigación" (Asociación Antropológica Americana 1998: 3).

Esta modalidad de cine procura que el proceso creativo e investigativo se realice compartiendo experiencias y saberes, generando reciprocidad y horizontalidad, en contraposición a posturas jerarquizadas verticales. Gracias a ello, se consigue una investigación más completa y se revalorizan las tradiciones culturales, la autoestima y la identidad de la comunidad. Para alcanzar estos objetivos, el realizador debe tener cierta sensibilidad, humildad y curiosidad ante la presencia del "otro" y de su cultura. Así mismo, es fundamental que posea una experiencia previa que le permita mirar (etno)cinematográficamente la realidad que le rodea (fig. 5).

El cine compartido propone un diálogo intercultural en el que, ambas partes, realizador y comunidad, se enriquecen gracias a la interacción y la colaboración, ya que "no basta con observar, el cine etnográfico debe ser participativo" (Rouch 2003: 141, 220). El investigador no debe limitar su trabajo a la observación, pues quiéralo o no, va a ser parte de su propia investigación participando en una red comunicativa (Ardèvol 1994). Un audiovisual etnográfico no es solo el reflejo en imágenes de una cultura, sino que evidencia la relación intercultural y el entrecruzamiento de miradas del realizador y del sujeto filmado, con el fin de explicar la organización social y las pautas culturales de la comunidad estudiada (MacDougall 1994).

$\mathrm{Al}$ momento de iniciar un trabajo etnográfico, el investigador puede optar por el uso de las tecnologías audiovisuales, por una metodología textual o por ambas. Si decide utilizar las primeras, debe ser consciente de sus 


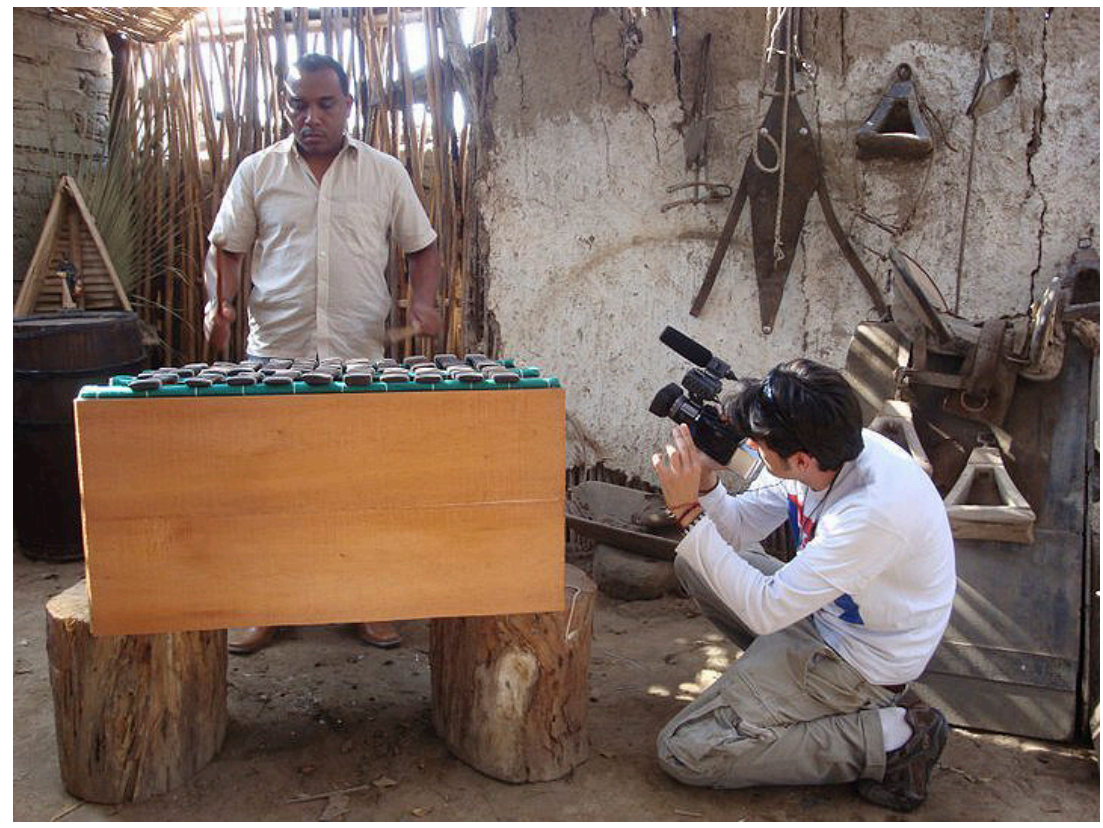

Figura 5. Realización de cine etnográfico compartido. (Fotografía: Gisella Burga). Figure 5. Filming of shared ethnographic cinema. (Photograph: Gisella Burga). ventajas e inconvenientes, ya que al introducir la cámara en la investigación se alteran "los fenómenos sociales y las realidades culturales” (Ardèvol 1997: 153). Por ello, hay que estar convencido de que es la mejor opción para la investigación que se va a desarrollar.

Para el cine compartido la cámara no es una simple herramienta auxiliar, ya que su introducción en la investigación antropológica condiciona tanto el plan de investigación, como el trabajo de campo, además de la relación del investigador con el lugar, la interacción con los habitantes de la comunidad, la construcción del análisis de los datos y la difusión del producto final. Cada plano que se graba, no es solo un trozo de cinta de video, sino que mucho más; es el resultado de la mirada del realizador, de su investigación, de su síntesis y de la interacción. Por esto, todos los planos del documental deben tener significado y transcendencia.

Si un investigador decide realizar un audiovisual etnográfico compartido, propongo -al igual que Sorenson y Jablonko (1975) y France (1989)- introducir la cámara desde el inicio en el trabajo de campo, no solo para recoger datos, sino para que se convierta en un instrumento compartido, ya que la cámara colaborativa pasará de mano en mano grabando, jugando, creando vínculos y reforzando identidades.

En este tipo de cine, el proceso de realización no se basa en captar imágenes y observar la realidad, sino en crear imágenes y (re)construir la realidad de manera compartida. Considero que la interpretación cultural se construye, no se graba. Por ejemplo, "en los Andes se pueden registrar muchas pautas culturales, pero no se puede grabar un rasgo fundamental como es la reciprocidad" (Montes del Castillo 2001: 79-87). Durante la creación de un audiovisual etnográfico no se puede grabar ilimitadamente. Esto nos obliga a reflexionar y seleccionar lo que es realmente importante de registrar. Igualmente, en la fase de edición hay que seleccionar los planos más adecuados y darles una duración precisa. Por lo tanto, la interpretación cultural se logra a través de la selección de las imágenes, cuando se está grabando, y en la ordenación de estas, durante la edición del documental.

Es necesario que el investigador exponga y justifique en el plan de investigación, en la monografía y en las proyecciones, cómo y cuándo utiliza la cámara, qué tipo de colaboración y qué modelos de representación son los más idóneos para desarrollar su investigación. ${ }^{24}$

Un aspecto fundamental es definir el modo de difusión y de exhibición que tendrá el trabajo audiovisual. Considero muy adecuado que la difusión se haga a través de internet y de forma gratuita-siempre que sea posible y respetando los derechos de autor, si los hay-. Esta es una decisión hay que consultarla y consensuarla siempre con la comunidad. 
Una vez finalizado el documental es recomendable ofrecer una proyección en el lugar donde se grabó, invitando a todas las personas de la comunidad. Esta es una forma de devolver el video a la gente, cerrando el círculo que se inició al comenzar el trabajo de campo. Un audiovisual antropológico es un viaje compartido, lo iniciamos solos, pero lo terminamos en comunidad.

Algunos de los pasos fundamentales para la realización del cine compartido son:

1. Plantear, debatir y consensuar con las comunidades o grupos humanos indígenas, la realización de un audiovisual etnográfico compartido, mediante procedimientos de consulta a sus autoridades ancestrales $\mathrm{u}$ otros mecanismos. ${ }^{25}$

2. Elaborar con la comunidad un plan de investigación y un diseño de preproducción audiovisual.

3. Realizar un trabajo de campo intensivo donde se desarrolle una observación participante.

4. Realizar talleres de fotografía, vídeo, lenguaje audiovisual, edición y distribución a la comunidad.

5. Ejercicios de fotografía junto con la comunidad.

6. Grabación compartida y visionado de las imágenes registradas junto con la comunidad. ${ }^{26}$

7. Interpretación cultural y construcción del audiovisual conjunta.

8. Edición del documental junto con la comunidad.

9. Entrega de los resultados de la producción y del estudio a través de proyecciones, publicaciones y medios de difusión, tanto a la comunidad como al público en general.

\section{La metodología de la cámara colaborativa en el cine etnográfico compartido}

Jean Rouch defendía la colaboración con sus protagonistas, a través de una cámara participante durante la filmación. Sin embargo, el control del resultado final del documental estaba en manos del director. En el proyecto Navajo film themselves, Worth y Adair prestaron cámaras a los nativos para que realizaran películas de manera independiente, sin la participación de los investigadores, pero posteriormente, estos las analizaban e interpretaban. Como se puede observar, no constituía un trabajo conjunto, salvo en la etapa de enseñanza y de aprendizaje de las herramientas audiovisuales.

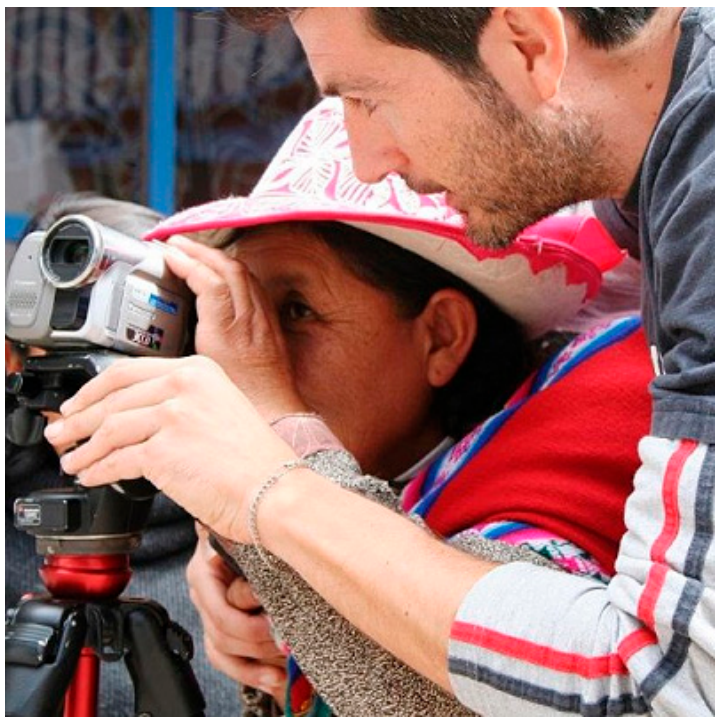

Figura 6. La cámara colaborativa del autor y Guadalupe Cuba Huamani, Defensora Comunitaria de Cusco. (Fotografía: Asociación Quisca). Figure 6. The collaborative camera of the author and Guadalupe Cuba Huamani, Community Advocate of Cusco. (Photograph: Quisca).

Esto difiere del cine compartido, ya que este propone que los protagonistas de un audiovisual etnográfico muestren su cultura y cosmovisión a través de la cámara, grabando sus propias imágenes y participando en la edición del documental. Por esta razón, es fundamental que el investigador desarrolle programas de capacitación y talleres para enseñar y compartir con la comunidad sus conocimientos en el manejo de la cámara, en edición y en lenguaje audiovisual (fig. 6). Una vez que aquella posea los conocimientos necesarios podrá plasmar, en el documental, su cosmovisión. De esta manera, la relación con el investigador será más igualitaria.

$\mathrm{Al}$ hablar de cámara colaborativa, no me refiero al hecho de compartir el aparato, sino a una manera de hacer video etnográfico. Se trata de construir conocimiento de manera conjunta, aprendiendo y enseñándonos los unos a los otros, democratizando el proceso creativo e investigativo, cimentando reciprocidad y compartiendo experiencias. El cine compartido potencia la revalorización de las tradiciones culturales, la autoestima y la identidad de una comunidad. A través de esta metodología, el realizador y los protagonistas se conocen, se reconocen, aprenden y construyen de manera compartida, a lo largo de todas las etapas de la investigación y de la difusión del estudio, desde el trabajo 
de campo, hasta las proyecciones y las publicaciones de los videos en internet.

Con respecto a estos últimos, propongo una postproducción y una publicación interactiva del audiovisual etnográfico. El objetivo de este método es introducir, en el DVD y en la versión online del documental (Web-doc), ${ }^{27}$ videos con información etnográfica complementaria que, por diversos motivos (por ejemplo, construcción dramática o excesiva duración), no se incorporaron al mismo. Las ventajas de esta herramienta interactiva son enormes, ya que permite añadir numerosos videos anexos al documental (incluso unos dentro de otros) y, por tanto, incorporar a la investigación mucha información relacionada y pertinente..$^{28}$ Algunos ejemplos de esta metodología se observan en el audiovisual etnográfico Zaña, recuperando el pasado. La herencia musical africana en el norte de Perú. ${ }^{29}$

Uno de los objetivos del cine compartido es establecer una relación igualitaria, entregando cada parte lo mejor de sí para conseguir reflejar, de una manera más completa, el objeto de estudio. No se trata solo de mostrar la visión de la comunidad. Como profesionales de la antropología y de la comunicación nuestro deber es aportar la nuestra, elaborando una interpretación justificada y sistematizada que, al discutirla y consensuarla con la mirada de los protagonistas, resultará una verdadera síntesis de lo estudiado, construyendo un conocimiento más complejo y preciso.

En el documental El desguaze. Historia de una okupación (Expósito \& Burga 2007), luego de utilizar la metodología de la cámara colaborativa en una comunidad de jóvenes de un centro social "okupado", se concluyó conjuntamente que los valores sobre los que se fundamentaban sus relaciones y la base de sus ideales eran la horizontalidad -en contraposición al sistema capitalista-, la autoorganización y la solidaridad. Como estos resultados pertenecen al nivel interpretativo, para que el espectador comprendiera cuáles eran estos valores, en la edición del documental decidimos utilizar las grabaciones de las actividades donde se percibían los ideales mencionados, como por ejemplo, conciertos a favor de diversas causas solidarias, actividades gratuitas, asambleas, trabajos en el huerto, acondicionamiento de la biblioteca comunitaria, charlas realizadas a favor de colectivos discriminados o que han sufrido represalias. La suma de estas imágenes, más los argumentos expuestos en las entrevistas, reflejan al espectador los ideales de esta comunidad.
Otro ejemplo de cine compartido se puede observar en un fragmento del documental Zaña, recuperando el pasado. La herencia musical africana en el norte de Perú (2015a). ${ }^{30}$ La selección de los protagonistas, la construcción de las imágenes, el guión y la edición fueron un trabajo conjunto. Durante la realización de este vídeo democratizamos el proceso creativo e investigativo gracias a la reciprocidad y a la cámara colaborativa. El resultado -en parte gracias a esta etnomusicología audiovisual- fue que el instrumento musical llamado "checo" se declaró no solo patrimonio cultural del Departamento de Lambayeque, sino de todo Perú. ${ }^{31}$ Igualmente importante fue el hecho de que se revalorizaron las tradiciones culturales, la autoestima y la identidad de toda la comunidad afroperuana.

\section{La enseñanza de la antropología visual: la metodología de la cámara colaborativa}

En el cine compartido, la cámara se constituye en el nexo entre el equipo de investigación/grabación y los protagonistas del documental, para sumar reflexiones, construir conocimiento y conseguir un trabajo final más completo. Considero que ese mismo vínculo se debe establecer entre el profesor y los alumnos, en el ámbito de la enseñanza de la antropología visual, ya que, actualmente, siguen sin priorizarse las técnicas audiovisuales como medios de interacción y de reciprocidad, como instrumentos de investigación e interpretación cultural, y como medios de comunicación y difusión.

La experimentación reflexiva y teórica con la cámara debería ser parte de la formación de los estudiantes de Antropología. Es esencial que se expongan, de manera teórica y práctica, las diferentes maneras de utilizar la cámara, los modelos de colaboración con los informantes y los modos de representación del cine etnográfico. Es imprescindible que los alumnos consideren el análisis de los diferentes realizadores que han hecho aportes importantes a la antropología visual y al cine documental.

La base de esta propuesta pedagógica es la utilización de la cámara. Los alumnos deben llevar a cabo prácticas, tanto fotográficas como de video, e insertarlas en sus trabajos de investigación. Al igual que cuando nos enseñan a escribir aprendemos las normas sintácticas y gramaticales, la antropología visual se aprende analizando películas, fotografiando, grabando y editando. Esta práctica servirá como iniciación al trabajo de campo y 
como preproducción del audiovisual. La fotografía se utilizará como medio de aproximación y como objeto de retroalimentación y reciprocidad, a través de una observación participante. La fotografía etnográfica es clave, tanto en una investigación desarrollada con la metodología de la cámara colaborativa como en la enseñanza de la antropología visual, ya que ayudará a encontrar historias, personajes, contextos y lugares. $\mathrm{Al}$ terminar la práctica se reflexionará sobre las fotografías logradas.

Para finalizar, ejemplificaré la metodología de la cámara colaborativa con la descripción del proyecto piloto denominado "Medios que conmueven", en el que participé el año 2011 capacitando a 25 defensores comunitarios de Cusco (Perú) en el uso de los medios audiovisuales.

Aplicando esta metodología, los defensores comunitarios participantes en el curso/taller (quienes nunca habían utilizado una cámara) realizaron un cortometraje documental para denunciar la violencia de género que sufrían muchas mujeres en sus comunidades rurales. ${ }^{32}$ En los primeros días del taller aprendieron de manera práctica a manejar la cámara, realizar entrevistas, utilizar el lenguaje audiovisual y construir un guion. En este proceso, los participantes eran entrevistadores y entrevistados, realizadores y protagonistas. La cámara se convirtió en el nexo entre todas las personas que participamos en la elaboración del documental. Este nexo fue tan sólido, que originó un desenlace totalmente inesperado, pero coherente con la metodología de la cámara colaborativa: la protagonista, una joven mujer que sufría de violencia machista por parte de su ex pareja, decidió denunciar su caso ante la justicia. Debido al vínculo que se creó al utilizar la cámara colaborativa, todos la acompañamos al juzgado: el profesor, los defensores y, por supuesto, la cámara como parte de la pequeña comunidad que se construyó. Siguiendo los principios de la cámara colaborativa, este documental se subió a internet para difundirlo de forma gratuita, y posteriormente, se organizó una proyección a la que asistieron todos los participantes y personas de otras comunidades aledañas a Cusco.

Actualmente, en los cursos de antropología visual que imparto, tanto el análisis teórico como el visionado de películas etnográficas y el uso de las cámaras fotográficas y de vídeo, son elementos fundamentales para desarrollar una educación de la mirada etnográfica y potenciar la participación, la investigación y la interacción. ${ }^{33}$
Ahora tenemos una cámara que nunca más será un simple objeto auxiliar: es el nexo, la red que teje las relaciones sobre la que se cimentará la investigación.

\section{CONCLUSIONES}

Durante más de un siglo se han planteado diferentes tipos de cine etnográfico y métodos en la enseñanza de la antropología visual. Es tiempo de hacer cine etnográfico dominando las herramientas audiovisuales, de compartir ese conocimiento con las comunidades, de construir conocimiento compartido abandonando las estructuras verticales, de difundir sin restricciones, dando voz y visibilidad a las comunidades que muchas veces no la poseen. El cine compartido potencia la práctica colectiva -gracias a la cual se refuerzan los lazos comunitarios y se regenera el tejido social-, aumenta la reciprocidad entre el investigador y la comunidad, hace crecer la autoestima y la autorrepresentación comunitaria, refuerza la identidad cultural y construye un conocimiento más completo. Gracias a la incorporación de la cámara colaborativa en la enseñanza de la antropología visual se mejorará el aprendizaje y se creará una educación popular que servirá para que las comunidades y los investigadores den a conocer la historia y la cultura de manera más precisa y compleja.

Quizás, con el cine compartido se consiga estar más cerca de la meta que, según Jorge Prelorán (1995: 134), debería tener todo antropólogo: "Obtener los conocimientos necesarios para poder mejorar la humanidad".

Agradecimientos Este artículo se ha beneficiado enormemente de las sugerencias y discusiones constructivas -teóricas y metodológicas- de Macarena López Oliva. Agradezco los comentarios de Gustavo de los Santos y Luis Bruzón. El aprendizaje personal y profesional junto a Luis Pancorbo, durante años, ha sido fundamental para la creación de este artículo.

\section{NOTAS}

${ }^{1}$ La palabra cine se utiliza referida genéricamente a todas las tecnologías que registran imágenes en movimiento.

${ }^{2}$ En 1948 se realizó en el Musée de l'Homme de París el primer encuentro de cine etnográfico. En aquella reunión Leroi-Gourhan se preguntó: “Existe realmente el cine etnográfico?", y luego él mismo se respondió: "Existe porque nosotros lo proyectamos" (Rouch 1975: 83). "Este acontecimiento se considera fundacional en la configuración de una 
comunidad de productores que se llaman a sí mismos etnocineastas, en la aceptación del cine dentro de las instituciones académicas y supondrá la apertura del debate sobre lo que es o debe ser el cine etnográfico" (Ardèvol 2006: 68).

${ }^{3}$ Ver un fragmento de una de sus filmaciones: <https:// www.youtube.com/watch? $\mathrm{v}=1 \mathrm{R} 7 \mathrm{Jo} 0 \mathrm{om} 5 \mathrm{vQ}>$ [consultado: 09-07-2020].

${ }^{4}$ Se puede ver un ejemplo a partir del minuto $20^{\prime} 00^{\prime \prime}$ : $<$ https://www.youtube.com/watch?v=_f8J9NRchOE > [consultado: 09-07-2020].

${ }^{5}$ Se puede ver un ejemplo a partir del minuto 2'54": $<$ https://www.youtube.com/watch?v=_f8J9NRchOE $>$ [consultado: 09-07-2020].

${ }^{6}$ Ver a partir del minuto $35^{\prime} 42 ":<$ https://www.youtube. com/watch?v=_f8J9NRchOE $>$ [consultado: 09-07-2020].

${ }^{7}$ Se puede observar un ejemplo a partir del minuto 32 ' 44 ": $<$ https://www.youtube.com/watch?v=3C-2RgK3WwA $>$ [consultado: 09-07-2020].

${ }^{8}$ Ver Trance and dance in Bali en: <https://www.youtube.com/watch?v=Z8YC0dnj4Jw $>$ [Consultado 09-07-2020].

9 Ver en: <https://www.youtube.com/watch?v=-aoxRsRQUfI> [consultado: 09-07-2020]. Analizar las siguientes secuencias: inicio y minutos $24^{\prime} 00^{\prime \prime}$ y $43^{\prime} 08^{\prime \prime}$.

${ }^{10}$ Ver en: <http://www.rtve.es/alacarta/videos/otrospueblos/otros-pueblos-yanomamis/1925950/> [consultado: 09-07-2020].

${ }^{11}$ Ver en el minuto 12'55' $:$ <https://www.youtube.com/ watch? $\mathrm{v}=$ onsBsvmcjFg $>$ [consultado: 09-07-2020].

${ }^{12}$ Ver en: <https://www.youtube.com/watch?time_ continue $=82 \& \mathrm{v}=$ nnQqxDTA04Y $>$ [consultado: 09-072020].

${ }^{13}$ Ver un ejemplo de cinéma vérité en Historias de la esclavitud en Zaña, Perú: <https://www.youtube.com/ watch?v=5_m_Z6SPko> [consultado: 09-07-2020].

${ }^{14}$ Ver la introducción de La pyramide humaine (1959): $<$ http://vimeo.com/24140878> [Consultado 09-07-2020].

${ }^{15}$ Ver en: <https://www.youtube.com/watch? $\mathrm{v}=\mathrm{fCl}-$ 5nKYkTI> [consultado: 09-07-2020].

${ }^{16}$ Ver a partir del minuto $15^{\prime} 45^{\prime \prime}:<$ https://www.youtube. com/watch?v=onsBsvmcjFg $>$ [consultado: 09-07-2020].

${ }^{17}$ Ver en: <https://www.youtube.com/watch?v=kkqkaQt1O8> [Consultado 09-07-2020].

$18<$ http://www.veoh.com/watch/v95795145sbRh97Ax> [consultado: 09-07-2020]. Minutos 3'35" y 31'00".

$19<$ https://www.youtube.com/watch?v=wP7ZBtJ5rAw> [consultado: 09-07-2020].

${ }^{20}<$ https://www.youtube.com/watch? $=$ jAD2Bqu5v3c> [consultado: 09-07-2020].

${ }^{21}$ Ver Baraka (1992) de Ron Fricke en: <https://www. youtube.com/watch?v=NgGnRZPKRhQ> [consultado: 0907-2020].

${ }^{22}$ Ver Reassemblage (1983) de Trinh Minh-Ha en: $<$ http://zoowoman.website/wp/movies/reassemblage-fromthe-firelight-to-the-screen/> [consultado: 09-07-2020].
${ }^{23}$ Ver en: <https://www.youtube.com/ watch?v=LS9BEyQxyTY> [consultado: 09-07-2020].

${ }^{24}$ Es altamente recomendable realizar una monografía ya que, si el documental etnográfico va acompañado por ella, el trabajo de investigación será más completo y preciso.

${ }^{25}$ Según el Convenio sobre Pueblos Indígenas y Tribales -No 169-, aprobado por la oit en 1989, que entró en vigor el 05 septiembre de 1991.

26 "Los antropólogos deben determinar anticipadamente si la información entregada por sus anfitriones ha de permanecer anónima o recibir público reconocimiento, y deben hacer todo el esfuerzo necesario para responder a los deseos de quienes proporcionan la información. Los investigadores deben señalar a los participantes de sus investigaciones los posibles impactos que se desprenden de sus informaciones, y dejar en claro que a pesar de sus mejores esfuerzos, el anonimato puede verse comprometido o que el reconocimiento puede no materializarse" (Asociación Antropológica Americana 1998: 4).

27 "Web-doc", documental interactivo o multimedia es una producción documental que permite almacenar variedad de recursos con el fin de posibilitar la interacción con los receptores del audiovisual. En el Web-doc se pueden incluir entre sus apartados o menús, fotos, videos, audios, mapas, textos o cualquier información que se considere oportuna.

${ }^{28}$ Para desarrollar esta metodología es necesario adquirir un programa de postproducción de video; sin embargo, YouTube da la posibilidad de insertar de manera gratuita un ícono (tarjeta) en el documental, el cual, al cliquear, lleva de manera inmediata a otro vídeo.

${ }^{29}$ Ver link en nota 20. En el minuto 3'50" aparece un ícono en la imagen superior derecha, que, si se cliquea, lleva a un vídeo que amplía la información que da uno de los protagonistas. En el minuto 31'38" aparece nuevamente el ícono, al pulsarlo se abre un video que analiza el "baile tierra", una danza peruana extinta que se está intentando recuperar.

${ }^{30}$ En principio fue un video que se incluyó en el expediente que presentaron la Municipalidad Distrital de Zaña y el Museo Afroperuano a la Dirección Regional de Cultura de Lambayeque, solicitando que un instrumento musical afroperuano, el "checo", fuera declarado patrimonio cultural de la región de Lambayeque. Esta secuencia (minuto 24'45”, link en nota 20) se construyó siguiendo la metodología de la cámara colaborativa entre los investigadores y los miembros del Museo Afroperuano de Zaña.

${ }^{31}$ La resolución del Ministerio de Cultura de Perú se puede ver en: <http://zanateespera.blogspot.com.es/2011/12/elcheco-es-declarado-patrimonio.html $>$ [consultado: 09-072020].

${ }^{32}$ Ver en: <https://www.youtube.com/ watch? $\mathrm{v}=\mathrm{xS1C7wSe} 4 \mathrm{Uo}>$ [consultado: 09-07-2020].

33 Los resultados de estos cursos se pueden ver en: $<$ https://javierexpositomartin.wordpress.com/> [consultado: 09-07-2020]. 


\section{REFERENCIAS}

Achbar, M. \& Аввотт, J. 2003. La corporación, instituciones o psicópatas. $145 \mathrm{~min}$. Big Picture Media Corporation, Canada. ARDÈVOL, E. 1994. La mirada antropológica o la antropología de la mirada: de la representación audiovisual de las culturas a la investigación etnográfica con una cámara de vídeo. Tesis para optar al grado de Doctora en Antropología, Universidad Autónoma de Barcelona.

ARDÈVOL, E. 1997. Representación y cine etnográfico. Quaderns de l'Institut Català d'Antropologia 10: 125-168.

Ardèvol, E. 1998. Por una antropología de la mirada: etnografía, representación y construcción de datos audiovisuales. Revista de Dialectología y Tradiciones Populares LIII (2): 217-240.

Ardèvol, E. 2006. La búsqueda de una mirada: antropología visual y cine etnográfico. Barcelona: Uoc.

Asch, T. \& Chagnon, N. 1975. The ax fight. $30 \mathrm{~min}$. Documentary Educational Resources, EE.UU.

Asociación Antropológica Americana. 1998. Código de Ética de la Asociación Antropológica Americana. D. Guerra \& J. C. Skewes, Trads. Valdivia, 1 de marzo de 2003. <http://sgpwe.izt.uam.mx/files/users/uami/lauv/ codigo_de_etica_AAA_def.pdf $>$ [consultado: 15-07-2020].

BANKs, M. 2008. Los datos visuales en investigación cualitativa. Madrid: Morata.

Bateson, G. \& Mead, M. 1952. Trance and dance in Bali. 20 min. Nueva York University Film Library, EE.UU.

BERMúDEZ, B. 2013. CLACPI: una historia que está pronta a cumplir 30 años de vida. Revista Chilena de Antropología Visual 21: 20-31.

Bounaben, M. 2014. Entre el arte y la investigación. Improvisación, dialogismo y fabulación en Moi, un noir (Jean Rouch, 1958). Cine Documental 10: 6-26.

BRUzón, L. 2016. Los guardianes del tiempo. 34 min. AECIDDEMUCA, Guatemala.

BRUZÓN, L. 2017. Audiovisual etnográfico y tradición: una contribución a la identidad y al desarrollo del municipio. La experiencia de San Juan Atitán (Guatemala). Universitas XV (27): 45-65.

Cárdenas, C. \& Duarte. C. 2011. Etnografía de la comunicación audiovisual: un balance de las relaciones entre reflexividad, imagen y antropología. Nexus Comunicación 10: $150-171$.

Chaputiz, E. 2013. Productores audiovisuales indígenas en Ecuador, una práctica integral de "cosmovisión". Revista Chilena de Antropología Visual 21: 118-135.

Comunidad de Zaragoza. 2013. Los herederos de Achaneh. 25 min. Universidad Popular Autónoma de Veracruz-La Milpa Producciones, Mexico.

CraWford, P. 1992. Film as discourse: the invention of anthropological realities. In Film as ethnography, P. Crawford \& D. Turton, Eds., pp. 66-82. Manchester-New York: Manchester University Press.
Defensores Comunitarios de las Provincias de Paruro Y Cusco. 2011. Defensores comunitarios luchan en contra de la violencia familiar. $8 \mathrm{~min}$. Asociación Quisca-Guarango Cine y Video-IDL-Codecc, Peru.

De France, C. 1989. Cinéma et Anthropologie. Paris: Fondation de la Maison des Sciences de l'Homme.

EATON, M. 1979. The production of cinematic reality. In Anthropology -reality-cinema. The films of Jean Rouch. M. Eaton, Ed., pp. 40-53. London: British Film Institute.

Expósito, J. \& Burga G. 2007. El Desguaze. Historia de una okupación. 53 min. Utopikadoc, Spain.

Expósito, J. 2014. Historias de la esclavitud en Zaña. $10 \mathrm{~min}$. 1Frame Producciones, Peru.

Expósito, J. 2015a. Zaña, recuperando el pasado. La herencia musical africana en el norte de Perú. 35 min. 1Frame Producciones, Spain.

Expósito, J. 2015b. Ventarrón, un proyecto de vida. Arqueología e identidad lambayecana. 33 min. 1Frame Producciones. Spain.

Flaherty, R. 1922. Nanook of the North. 70 min. Révillon Frères, Paris, Canada.

Flaherty, R. 1948. Louisiana Story. 78 min. Robert Flaherty Productions Inc., EE.UU.

FrICKE, R. 1992. Baraka. 100 min. Magidson Films, EE.UU.

GLEYZER, R. 1974. Me matan si no trabajo y si trabajo me matan. 20 min. Grupo Cine de la Base, Argentina.

GraU, J. 2008. El audiovisual como cuaderno de campo. Documentos СІDов Dinámicas Interculturales 12: 13-30.

GRAU, J. 2012. Antropología audiovisual: reflexiones teóricas. Alteridades 22 (43): 161-175.

Guzmán, P. 1975. La batalla de Chile. 270 min. Chile.

Haddon, A. 1989. The Malo Ceremony. Cambridge: United Kingdom.

Halkin, A. 2006. Fuera de la óptica indígena: zapatistas y videístas autónomos. Revista Chilena de Antropología Visual 7: 71-92.

Heider, K. 1976. Ethnographic film. Austin: University of Texas Press.

Henley, P. 2001. Cine etnográfico: tecnología, práctica y teoría antropológica. Desacatos: lo visual en antropología 8: 17-36.

HenríqueZ, E. 2017. El etnógrafo y la cámara en la producción audiovisual de productores informales. Universitas XV (27): 93-115.

JACKINS, I. 1988. Margaret Mead \& Gregory Bateson in Bali: their use of photography and film. Cultural Anthropology 3 (2): 160-177.

LA PLATAFORMA. 2007. Cso La Traba primer año de okupación. 50 min. La Plataforma, Spain.

Lisón, C. 2014. Algunas reglas para la construcción de un audiovisual antropológico. Anales del Museo Nacional de Antropología xvi: 28-44.

Macdougall, D. 1994. Whose story is it? In Visualizing theory: selected essays, L. Taylor, Ed., pp. 27-36. London: Routledge.

Marcus, G. \& Fischer. M. 1986. Anthropology as cultural 
critique: an experimental moment in the human sciences. Chicago: Universidad de Chicago Press.

Marshall, J. 1958, The Hunters. 72 min. Texture Films Inc., EE.UU.

MeAd, M. 1963. Anthropology and the camera. In Encyclopedia of Photography. W. D. Morgan, Ed., p. 174. New York: Greystone Press.

Meneses, M. 1994. Wichan: el juicio. 25 min. Kien Producciones, Chile.

Minh-HA, T. 1983. Reassemblage. 40 min. Women Make Movies, EE.UU.

Minh-HA, T. 1990. The totalizing quest of meaning. In Theorizing documentary, M. Renov, Ed., p. 21. New York: Routledge.

Montes del Castillo, A. 2001. Films etnográficos. La construcción audiovisual de las 'otras culturas'. Comunicar 16: 79-87.

Mora, P. 2015. Poéticas de la resistencia. El video indígena en Colombia. Bogota: Cinemática distrital.

MORRIs, R. 1994. New worlds from fragments: film, ethnography, and the representation of northwest coast cultures. Oxford: Westview Press.

Nichols, B. 1991. Representando la realidad: problemas y conceptos en el documental. Bloomington: Indiana University Press.

Nichols, B. 2001. Introduction to Documentary. Bloomington: Indiana University Press.

Pancorbo, L. 1983/2010. Otros pueblos. Serie de rtve, Spain.

Pennebaker, D. 1965. Don't look back. 96 min. LeacockPennebaker, EE.UU.

Prelorán, J. 1995. Conceptos éticos y estéticos en el cine etnográfico. In Imagen y Cultura. Perspectiva del cine etnográfico. E. Ardèvol \& L. Pérez Tolón, Eds., pp. 123-159. Granada: Diputación Provincial de Granada.

Pueblo indígena Kuikuro. 2004. O dia em que a lua menstruou. 28 min. Vídeo nas Aldeias, Brazil.

RodRIgo-MendizÁBAL, I. 1996. El vídeo como instrumento de investigación social: la antropología visual como metodología. Texto introductorio al curso sobre Lectura de la Imagen desde la Antropología Visual en la Universidad Nur, Santa Cruz de la Sierra. <http://ivanrodrigo. wordpress.com/2009/02/15/el-video-como-instrumentode-investigacion-social-la-antropologia-visual-comometodologia/> [consultado: 09-07-2020].

Rouch, J. 1959. La pyramide humaine. 90 min. Les Films de la Pléiade, France.

Rouch, J. 1961. Chronique d'un été. 85 mim. Argos Films, France.

Rouch, J. 1975. Les maîtres fous. 35 min. Documentary Educational Resources, France.

Rouch, J. 1975. The camera and man. En Principles of visual anthropology, P. Hockings, Ed., pp. 29-46. The Hague: Mouton Publishers.

Rouch, J. 2003. Ciné-ethnography. Minnesota: University of Minnesota Press.
RuBy, J. 1980. Franz Boas and early camera study of behavior. Kinesics Reports 3 (1): 6-11.

Ruby, J. 1995. Revelarse a sí mismo: reflexividad, antropología y cine. In Imagen y cultura. Perspectivas del cine etnográfico, E. Ardèvol \& L. Pérez Tolón, Eds., pp. 161-201. Granada: Diputación Provincial de Granada.

Ruby, J. 1996. Antropología visual. Revista Chilena de Antropología Visual 2: 154-167.

Ruby, J. 2007. Los últimos 20 años de antropología visual - una revisión crítica. Revista Chilena de Antropología Visual 9: 13-36.

SANDOVAL, J. 2017. Investigación colaborativa y de-colonización metodológica con cámaras de video. Universitas xv (27): 161-177.

SANJINÉs, I. 2013. Usando el audiovisual como estrategia de sobrevivencia y de lucha, de creación y recreación de un imaginario propio. Revista Chilena de Antropología Visual 21: 32-50.

Scherbovsky, N. 2017. "La batalla de Chile": acción, movimiento, lucha de clases y ocaso de una revolución. In $\mathrm{La}$ Tinta. <https://latinta.com.ar/2017/05/la-batalla-de-chileaccion-movimiento-lucha-de-clases-y-ocaso-de-unarevolucion-ii/> [consultado: 09-07-2020].

Sorenson, R. \& JABLONKo, A. 1975. Research filming of naturally occurring phenomena: basic strategies. En Principles of visual anthropology, P. Hockings, Ed., pp. 151-163. The Hague: Mouton Publishers.

The navajo film themselves. 1966. Museum of Modern Art, Arizona. EE.UU.

Turner, T. 1990. Visual media, cultural politics and anthropological practice: some implications of recent uses of film and video among the Kayapó of Brasil. CVA Review: 8-12.

Turner, T. 1992. Defiant images. The kayapo appropriation of video. Anthropology Today 8 (6): 5-16.

VArda, A. 2000. Les glaneurs et la glaneuse. $82 \mathrm{~min}$. CinéTamaris, Francia.

Vertov, D. 1929. El hombre de la cámara. 68 min. vUfKu, URSS. Vertov, D. 1963. Kinoki Perevorot. Cahiers du Cinéma 144: 32-34. Vertov, D. 1974. El cine ojo. Madrid: Fundamentos.

Villafaña, A. 2013. La auto representación se ha vuelto una necesidad en el video indígena: protección a la propiedad colectiva. Revista Chilena de Antropología Visual 21: 136-144.

WorTH, S. \& ADAIR, J. 1972. Through navajo eyes: an exploration in film communication and anthropology. Bloomington: Indiana University Press.

Wortham, E. Más allá de la hibridad: los medios televisivos y la producción de identidades en Oaxaca, México. $L i$ minaR 3: 34-47.

Young, C. 1975. Observational cinema. In Principles of visual anthropology, P. Hockings, Ed., pp. 65-82. The Hague: Mouton Publishers.

ZIRIón, A. 2015. Miradas cómplices: cine etnográfico, estrategias colaborativas y antropología visual aplicada. Revista de Ciencias Sociales y Humanidades 78: 45-70. 